\title{
The Assessment of Cities Physical Complexity through Urban Energy Consumption
}

\author{
Mustafa Aziz Amen \\ College of Arts and Science, Design Department, The American University of Kurdistan, Kurdistan Region, Duhok, Iraq
}

Received January 6, 2021; Revised June 11, 2021; Accepted October 17, 2021

\section{Cite This Paper in the following Citation Styles}

(a): [1] Mustafa Aziz Amen, "The Assessment of Cities Physical Complexity through Urban Energy Consumption," Civil Engineering and Architecture, Vol. 9, No. 7, pp. 2517 - 2527, 2021. DOI: 10.13189/cea.2021.090735.

(b): Mustafa Aziz Amen (2021). The Assessment of Cities Physical Complexity through Urban Energy Consumption. Civil Engineering and Architecture, 9(7), 2517 - 2527. DOI: 10.13189/cea.2021.090735.

Copyright $\bigcirc 2021$ by authors, all rights reserved. Authors agree that this article remains permanently open access under the terms of the Creative Commons Attribution License 4.0 International License

\begin{abstract}
Complex systems analysis is a widely used technique for assessing urban efficiency and sustainability of cities. However, sustainable cities need an effective energy management strategy based on regulations. This research aims to better understand sustainability efficiency of cities by establishing a link between complexity and urban energy consumption. The study demonstrated a technique for estimating physical complexity based on the built environment in an urban region. Accordingly, it applied quantitative measurements of complexity to urban form using empirical methods and information analysis. Consequently, the study evaluated urban complexity and energy consumption in cities using Simpson's variety index and the passive volume ratio. The researcher examined the relationship between complexity and energy use in two districts in Erbil; one is a traditional neighborhood, while the other is part of a modern grid system. The study found that increasing the physical complexity of urban tissue results in reduced urban energy consumption. Thus, there is a chance to comprehend urban energy efficiency with the physical complexity of the city. Consequently, the findings enable decision-makers to evaluate physical complexity using a sophisticated toolset to create more sustainable cities.
\end{abstract}

Keywords Urban Complexity, Urban Energy Consumption, Simpson's Diversity Index, Passive Volume Ratio

\section{Introduction}

Urban areas are home to more than half of the world's population [1]. Furthermore, cities are the primary sources of $\mathrm{CO}_{2}$ emission and pollution on earth, coming from many activities, and energy consumption is the most significant source of emissions [2]. Urban environmental issues like pollution and drastic energy consumption create a severe need for urban sustainability. One of the main criteria for creating sustainable cities is controlling energy consumption through specific strategies. [3]

Likewise, urban energy reduction became a significant issue, especially in the current environmental crisis and global warming.

Sustainability is related to urban structures composed of complex interactions between social, economic, cultural characteristics, energy resources, material flows, and flows at many temporal and spatial scales [4]. Such complexity presents a challenge to recognizing and coping with the causes of urban environmental issues without further degradation [5]. The assessment of urban complexity is a valuable tool for evaluating energy consumption of cities [6]. Based on the previous statement, the study aims to understand sustainable cities by recognizing the effect of urban physical complexity on energy consumption to aid decision-makers in the design development process. Hence, this study hypothesizes that understanding the actual relationship between urban physical complexity and energy consumption will be helpful to better spatial urban design toward more sustainable cities. The study aims to answer the following questions.

1) What is the proper method of assessing complexity in urban areas based on empirical paths?

2) What is the effect of physical complexity on urban energy consumption? 
Nonetheless, the study illustrates cities' complexity evaluation process combined with energy consumption to help identify decision-making levels to improve urban environmental quality. Accordingly, the study used a case study in Erbil city, the capital of the Kurdistan region of Iraq, to assess the assumptions about physical complexity assessment in the urban area and the environmental quality by providing energy consumption assessments of complex urban-environmental systems. To achieve and test the last goals, the research selects two locations in the city: one is traditional, while the other is a part of the grid system district with a standard grid layout. The objectives of the study are:

1) To identify the most significant measurable elements for assessing urban physical complexity.

2) To investigate tools to evaluate physical complexity in the urban area, expressing them in practical and mathematical innovative ways.

3) To study the most critical factors concerned with urban physical complexity that affect energy consumption and employ adequate tools to evaluate urban energy consumption in Erbil city.

\section{Materials and Methods}

\subsection{Efficient Urban Area}

Currently, urban areas consume about $75 \%$ of the world's supply of primary energy, which is estimated to rise considerably in the future due to urban growth. Access to sustainable and global energy is an urgent challenge for most of the world. So, realizing the patterns of urban energy consumption may help solve urban sustainability and energy security challenges. However, 40 percent of the global energy demand will come from increased electricity consumption by 2040 [7]. IEA (2019) stated that buildings account for $40 \%$ of the global energy use and about $30 \%$ of the $\mathrm{CO} 2$ emissions in cities worldwide [8].

Some strategies provide a good relationship with the sun path, get better natural lighting, and ventilation, attaining thermal, visual, and acoustic comfort can achieve Energy efficiency in urban areas [9]. In other words, through an angle of buildings, the passive solar design directly affects energy consumption by affecting the form and shape of the built environment [10]. Furthermore, urban density is an essential part of how cities work and a critical factor in urban energy use. Furthermore, choosing a suitable site location accessible by public transportation is vital [11], and open space services reduce energy consumption. It should be mentioned that mixed land use and building typology impact energy consumption in an urban area by affecting Diversity [12]-[17] See figure ' 1 '.

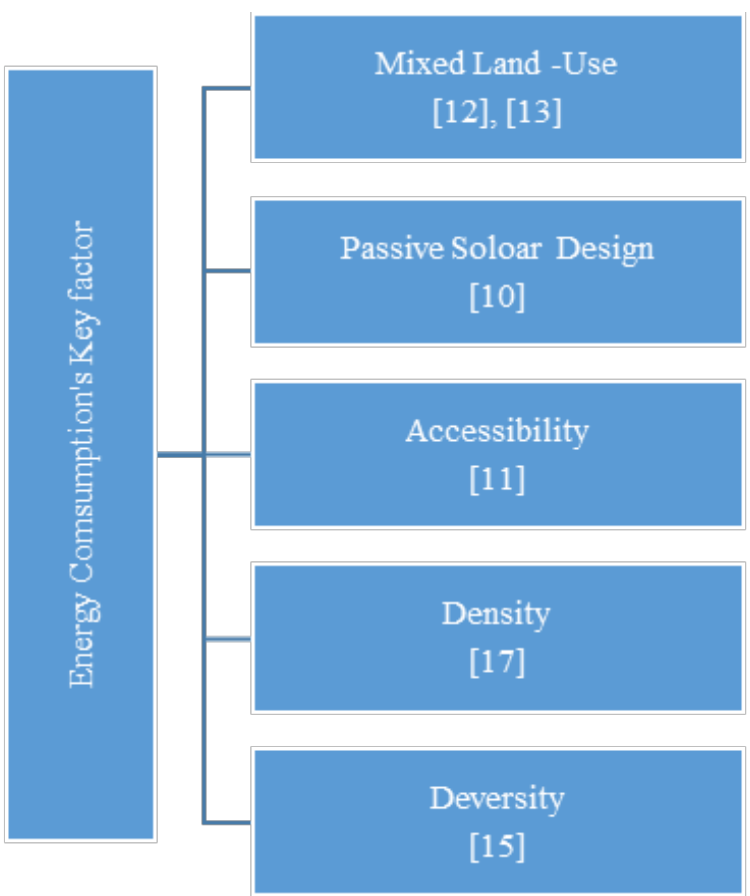

Figure 1. The most significant factors in urban energy consumption. (By Researcher)

Accordingly, the mentioned key factors are initial factors in evaluating energy consumption in any case study urban area.

\subsection{Complexity in Urban Development}

Complexity is a composite of heterogeneous components woven together and closely related, posing a contradiction between one and many [18]. The term "complexity" characterizes both processes, patterns, and configurations that emerge from numerous linked and interacting sub-components of a system [19]. Cities are apparent instances of complicated systems [20]-[22]. Also, Cities' operational complexity has long been a source of frustration for urban planners since it complicates urban research and design. Since the 1960s, system theory has been a standard approach to solving urban complexity; however, the early attempt of Ludwig V. Bertalanffy on General Systems Theory in 1968 and others have facilitated contributions to a systematic understanding of the urban area [23], [24].

The first generation of "large-scale urban models" emerged in the 1960s and 1970s due to inventive engagement in understanding urban systems [25]. Following the tested models of the 1960s, Urban designers have dealt with complexity utilizing conceptual, narrative, and simulation models; however, these models could not comprehend and replicate complicated urban functions [26]. Despite the difficulties analysts face, planners should assess complexity practically [24], though there are no big unified quantitative models [27].

The goal of addressing complexity within cities is to 
reconcile disparate and discontinuous forms of information [18]. Thus, complexity requires greater variety, connectivity, sustainability, and Diversity. Today, various urban design trends, such as new urbanism and smart growth, have embraced complexity [28], [29]. However, to maximize the advantages of complex systems, the urban design must adopt a more appropriate definition of complexity and quantify it to analyze the current state of urban regions and suggest developed alternatives.

\subsubsection{Assessment of Urban Complexity}

Through a literature review, many scholars have considered quantitative measures of the urban form, but without referring to complexity in an obvious way (e.g., [30]-[33]. literature is full of several metrics of complexity, from metropolitan to neighborhood to single building. Lloyd (2001) classified complexity metrics across a range of fields of investigation; following the same line, Bourdic et al. (2012), presented an overview of overall spatial indicators and cited the criteria for assessing LEED biology design [34]. At the same time, Parrott [35] and Salat et al. [6] surveyed cities' ecosystem complexity indicators. The following demonstrates complexity metrics at the level of urban design; accordingly, the metrics include temporal, visual, spatial, and structural measures usable for urban morphology.

\section{Temporal Measures}

It is related to form and physical design; this measure represents the time series and system dynamics, including the integrating time series into the domain, revealing underlying attractors, determining Lyapunov's exponents ${ }^{1}$, and analyzing the process from the perspective of 'information theory' [19], [36]. It examines how systems and behaviors change through time, human behavior that is unforeseen, and the development of cities. As a result, temporal measurements are common in traffic analysis, congestion, economic surges, crowd behavior/dynamics, population growth, and decline. Therefore, it does not help assess complexity through forms and parcels because it depends on time and changes throughout time.

\section{Visual Complexity}

This measure demonstrates how humans perceive the visual consistency, size of the built environment, attention, order, and clarity by assessing detailed vitality and human activity, the facade of buildings and signage, sun rays, and tree canopy patterns like an enclosure feeling. The basic concept is that slow-moving people require a high degree of complexity to keep their concentration, while fast-moving automobiles find the environment confusing.

Dumbaugh and Li [37] debate that urban structures that regulate traffic speed and conflicts and visual complexity will increase motorists' visibility, minimize accidents, and

1 It is a quantity describes the average of separation of infinitesimally close trajectories [49]. enhance pedestrian safety. However, Marshall (2008) suggests that urban settings with perceptual Diversity are fascinating and pleasant to humans, likely because human beings have evolved in natural circumstances with a significant level of visual complexity. In brief, the metric depends on human perception, which involves qualitative characteristics more than quantitative characteristics like the place and other essential characteristics.

\section{Structural Measures}

There are two types of structural measure, Fractal structure, and Network structure; the former implies the similarity of objects and the roughness and how the detail is linked to the scale studied within. In other words, it deals with the likeness of structures and patterns over different scales. The assessment methods of this type can be implemented through some parameters, e.g., differential measurements of city perimeter, roof texture, buildings, and streets of all sizes. Batty (2005) demonstrated that cities and urban periphery structures are fractal through the model of a network of urban streets [19]; the fractional measures shape the characteristics of visual Complexity [38]. Unlike abstract mathematical fractals, fractals do not exist optimally at all scales in the natural world (from the infinitely tiny to the infinite). Therefore, it cannot be applied effectively to cities while neglecting the whole [19].

The second type is "Network structure," which deals with cities and citizens' internal arrangement, connectivity, spreading through communication, substitution, patterns of people movement, the accessibility to the destination, streets permeability, connectivity, categories of intersections, and density [39]. The complexity of urban networks is quantified by studying the structure of urban networks, especially the density and connectedness, thus extending the toolkit of urban morphologists [29], [39]. A network is collectively referred to as nodes, and their connections are collectively referred to as edges [40]. A node in a road network indicates a junction or dead-end, while an edge represents the roadway section that links them (Boeing, 2017). This style is more concerned with the network of connections and mobility than with the physical structure of the structures.

\section{Spatial Measures}

Spatial metrics evaluate complexity by examining patterns of the system across time rather than reviewing several series, implying that they are static rather than dynamic; accordingly, the measurements focus on land and grain patterns, particularly their size and diversity. As a result, mixed land uses, social integration, parcel forms and sizes, and spatial dispersion of urban components are all measured [39]. dispersion and diversity are the most often used spatial complexity measures in urban planning [41]. Cervero and Kokelman assert that land use influences travel behavior[42], while, Salat classify spatial entropy in terms of urban complexity into three categories: 
comparable object diversity, spatial distribution diversity, size, scale, and variety[6]. Following the same line, Hayek et al. determined the urban neighborhood environment by combining land use and density [43]. This approach may offer a straightforward empirical method to assess urban complexity, which is the objective of this research. Refer to figure ' 2 '.

According to the literature, Diversity was identified half a century ago by Jacobs [41] as an intrinsic factor for livability, economic growth, and cities' attractiveness. Moreover, Diversity is one of the most fundamental variables in cities, not least when considered complex systems [41]. Simpson Diversity Index (SDI) measures the Diversity (entropy) of objects through space and is a popular indicator of the mixture of land use in urban design studies [39]. A high degree of Diversity exacerbates complexity of the system; however, urban Diversity may positively affect social consistency, economic effectiveness, and social movement in terms of social Diversity; Diversity is an essential factor for cities [4], [24], [44]. It is crucial to know how to evaluate descriptive complexification formulae for urban form and design. Cities as complex systems must provide high-quality indicators to initiate conversation and show flexibility, interconnection, and adaptation of existing and planned patterns and processes. Except this, there is no study on metrics relevant to urban design integrates concepts and techniques from planning and design with scholarly writing and practice. Data Analysts have used those metrics in the scientific community for a long time, but many remain unknown in design and research practice [39]. Because the present article focuses on physical complexity, the physical or spatial measure will be relevant to this research.

\subsubsection{Simpson's Index to calculate Diversity}

Many diversity metrics suffer from intense sample size or depending on the sampling effort, which is almost unavoidable with the abundance measures, including those developed to reduce the impact of increasing sample sizes collecting additional categories. To a lesser degree, it is also valid of several indices weighted toward Diversity's evenness element. The Simpson Index is one of the metrics that tend to be relatively independent of sample size [45] , the Simpson Diversity Index (SDI) is

$$
\text { Simpson Diversity Index }(\mathrm{SDI})=\frac{1}{\sum_{i=1}^{S} p i^{2}}
$$

Where $p$ is the proportion $(n / N)$, when one particular category is (n), and the total number of individuals is $(\mathrm{N})$, while (s) is the number of categories.

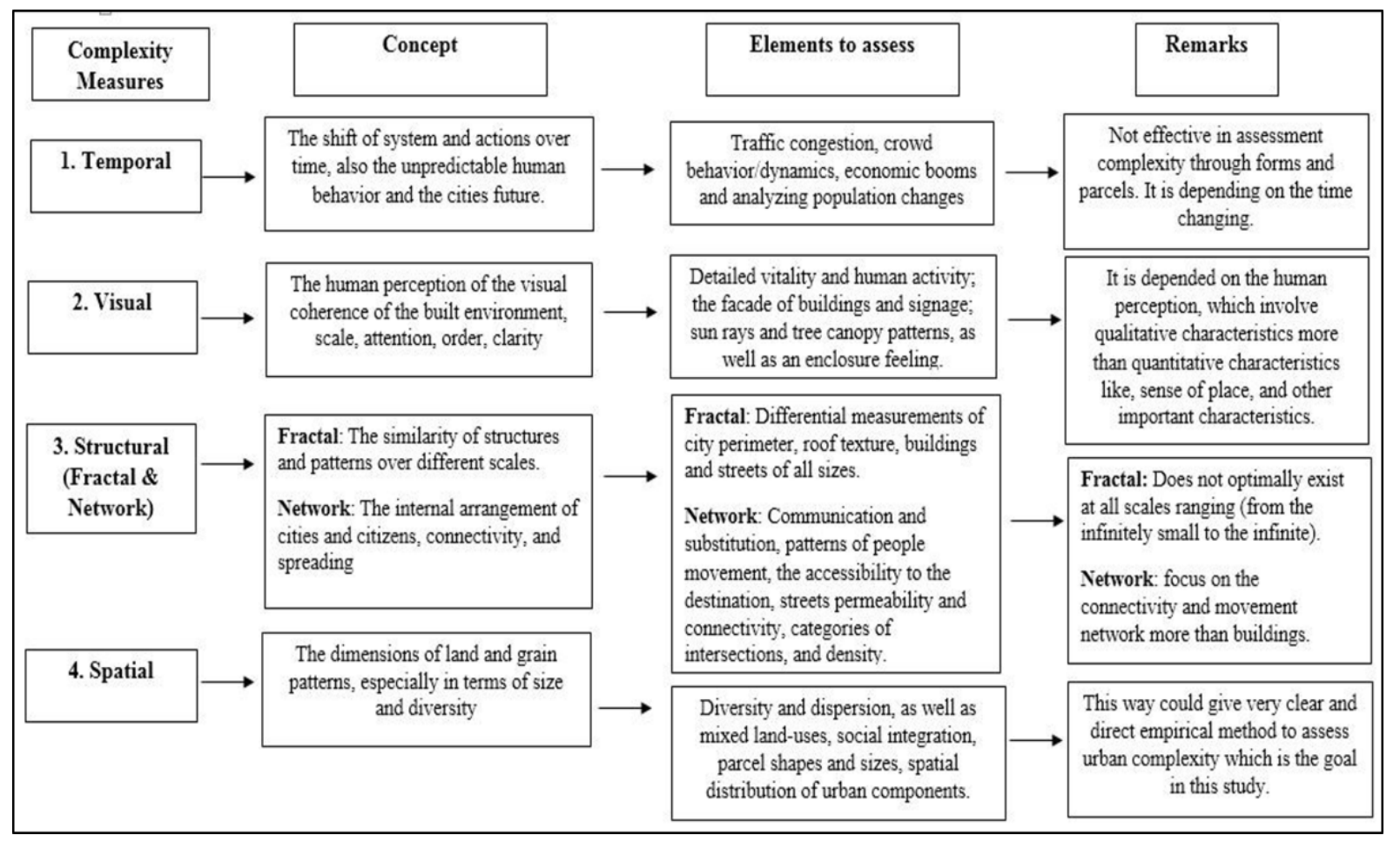

Figure 2. The quantitative framework for assessing urban complexity. (By Author) 


\subsubsection{Complexity for energy consumption evaluation}

Analysis of Complexity by the Diversity of urban fabrics helps formulate a final indicator connecting Complexity (or Diversity) and energy consumption. It includes quantifying the energy required to build complexity and, vice versa, quantifying the effect of complexity on energy usage. For this purpose, the research applied the passive zones in the buildings; according to the literature, the more Diversity, in terms of a building typology, scales, and land use, the more energy-efficient it is [18]. Analysts used the indicator to measure the energy consumption reduction due to complexity of the urban fabrics for assessing the relationship between complexity of the fabric and the demanded energy [6]. According to Salat and Bourdic [18], maximizing information amount (and thus its complexity) enables the related energy to be reduced.

Consequently, the complexity of urban fabrics plays a crucial role in reducing energy consumption. The fractal structure of urban fabrics works to minimize structural energy demands by optimizing complexity. Passive Volume Ratio (PVR) can be applied to evaluate the passive zone in an urban area. This tool aims to optimize the mediation between the building and the local environment, using passive zones as an example [18] See figure ' 3 '. The passive zone concept is described as the building area within a distance from an outer wall, commonly 6 to 8 meters, depending on the floor to ceiling [46]. According to the LT method, this classifies the buildings into passive zones and non-passive zones as per the location [47].

Passive zones benefit from natural ventilation and daylight and good solar gains in winter. Energy consumption of the buildings correlates with ventilation and lighting; therefore, energy consumption in these zones is expected to be lower because a significant part of lighting and cooling will be free. However, these zones will be suffering from heat loss/gain (loss of heat in the cold season and gain the heat in a hot season by solar radiation) through the building's envelope [48]. Nevertheless, with the development of construction technology now, especially concerning insulation and glass, the effect of this phenomenon on the total energy consumption will decrease significantly. On the strategic dimension, the function of passive zones will become more significant in the future. PVR is a characteristic of the building scale; however, considering this issue on the urban scale gives a motivating view.

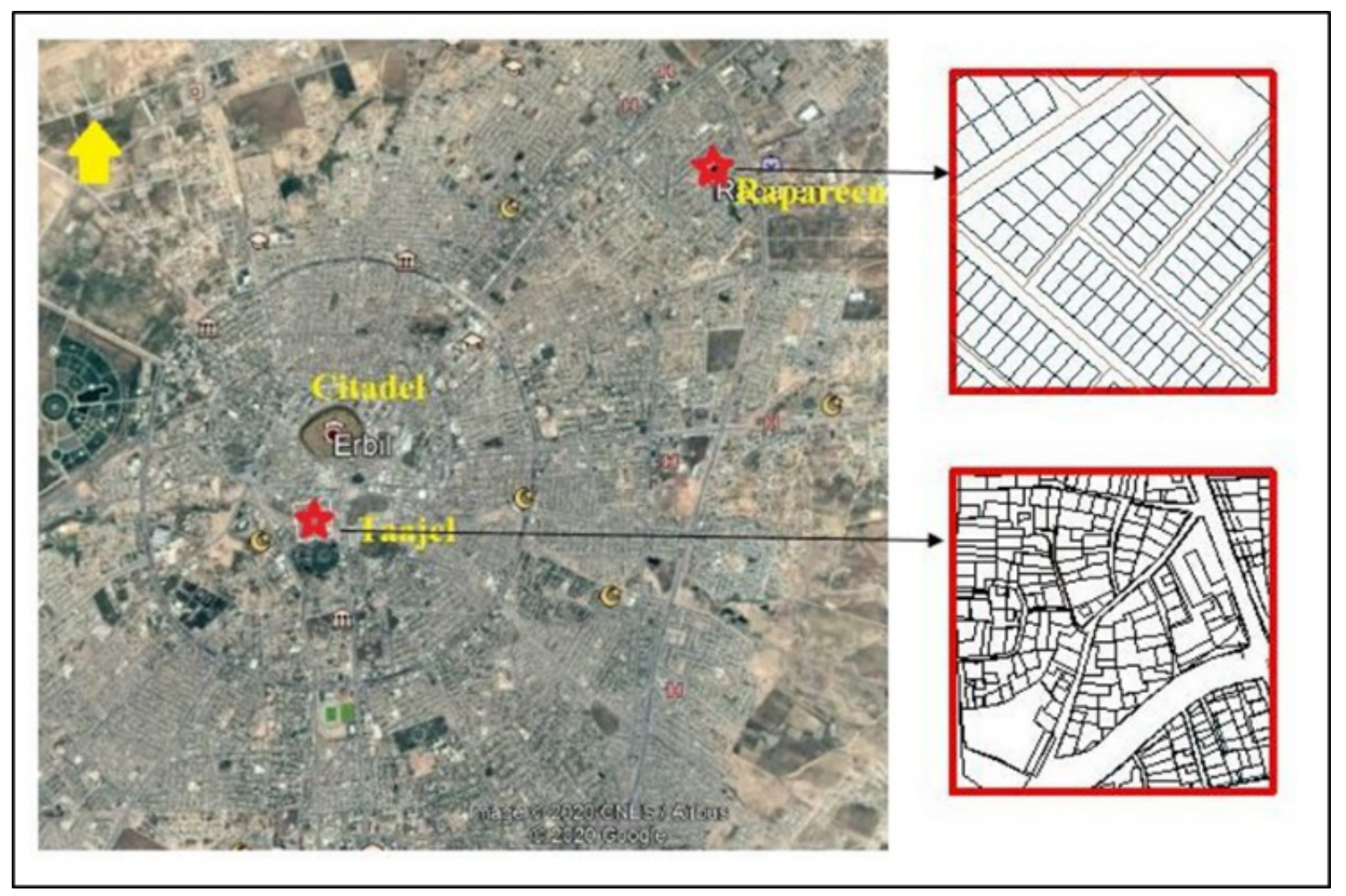

Figure 3. The location of the passive zone from the building façade [46] 


\subsection{Methodology}

The study's methodology has three parts; the first is to identify critical information to determine the most proper method to assess urban complexity according to the limit of the current studies and use the complexity as an index to evaluate energy consumption in urban areas. Urban Complexity assessment depends on three factors: Diversity, through Simpson's Diversity Index, as seen in formula (1). The study will focus on passive solar design in buildings as the main factor in evaluating energy consumption in urban areas determining the buildings as the most energy consumption sector in an urban area. Therefore, passive volume ratio PVR which is an analytical tool will be applied to evaluate energy consumption through the built form.

The second part is associated with the site selection by selecting two different sample areas in Erbil's city to apply analytical tools. The third part the analysis of the results, conclusion and answer questions of the study. See figure ' 4 '.

\section{Assessment of Urban Physical Complexity and their Effects on Energy Consumption}
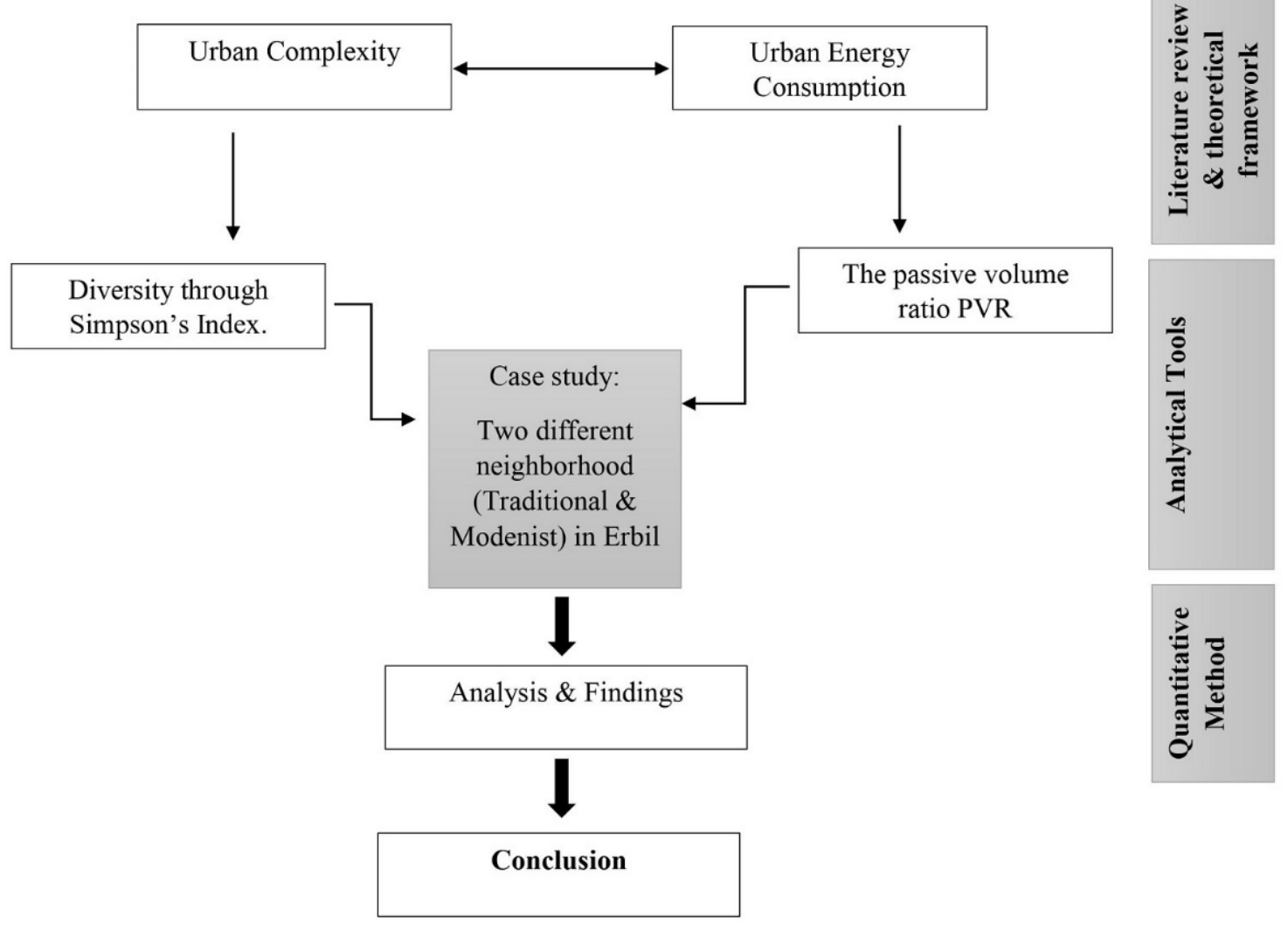

Figure 4. The methodology framework. (By Researcher) 


\subsection{Case Study}

The case studies are districts (200x200 m squares) in two neighborhoods in Erbil city, one is old (traditional) known (Tajfel), and the second is a modernist neighborhood known (Rapparee). The researcher selected the case studies basing on the neighborhood scale. Both neighborhoods are similar in the height of buildings and the type of functions, which is vital when making a comparison. Figure ' 5 ' demonstrates the case study areas within Erbil and shows the selected samples for studying and their urban textures.

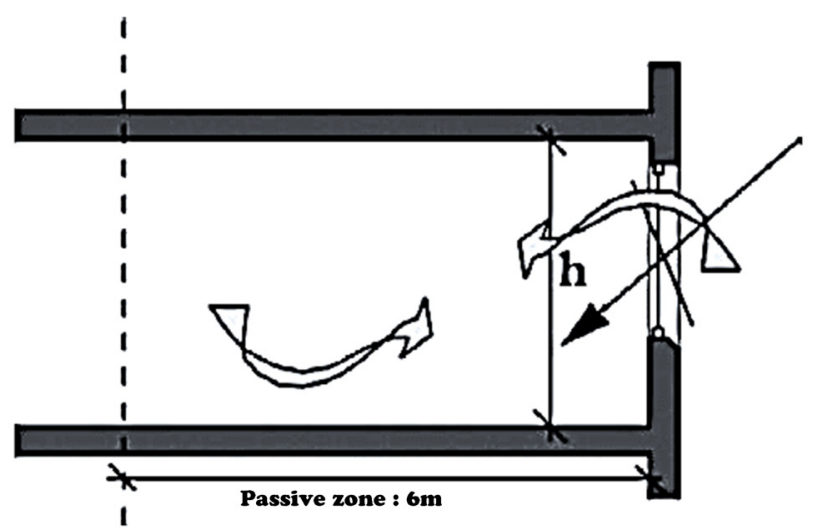

Figure 5. Location and plan of the selected parts from (Rapparee and Taajel) neighborhoods within Erbil, from Google earth. (Developed by Researcher)
As evident from the selected case studies, the study has investigated two urban tissues based on the geometric analysis. The first is traditional (Teasel), and the second is modernist (rapparees) in Erbil city. See figure 6.

\section{Results and Discussion}

The following analysis shows how the passive volume ratio may rise due to the urban fabric complexity increment. In this context, two zones at both neighborhoods in Erbil have been under consideration with a $200 \times 200 \mathrm{~m}$ square. The buildings and urban texture have been analyzed based on their complexity assessment using SDI tools and evaluating energy consumption using PVR tools to investigate the relationship between complexity and urban energy consumption.

\subsection{Complexity Assessment}

The criteria for investigating the Diversity in the selected case study areas were the land use and the buildings' functionality according to their categories and the width of the streets. The previous condition is significant as it provides the researcher with an evaluation tool through field observation and the analysis of the plans and maps.

Figure ' 6 ' demonstrates the land-use maps of the selected samples $(200 * 200 \mathrm{~m})$ in both case study areas in each neighborhood of 'Tajfel and Rapareen.'

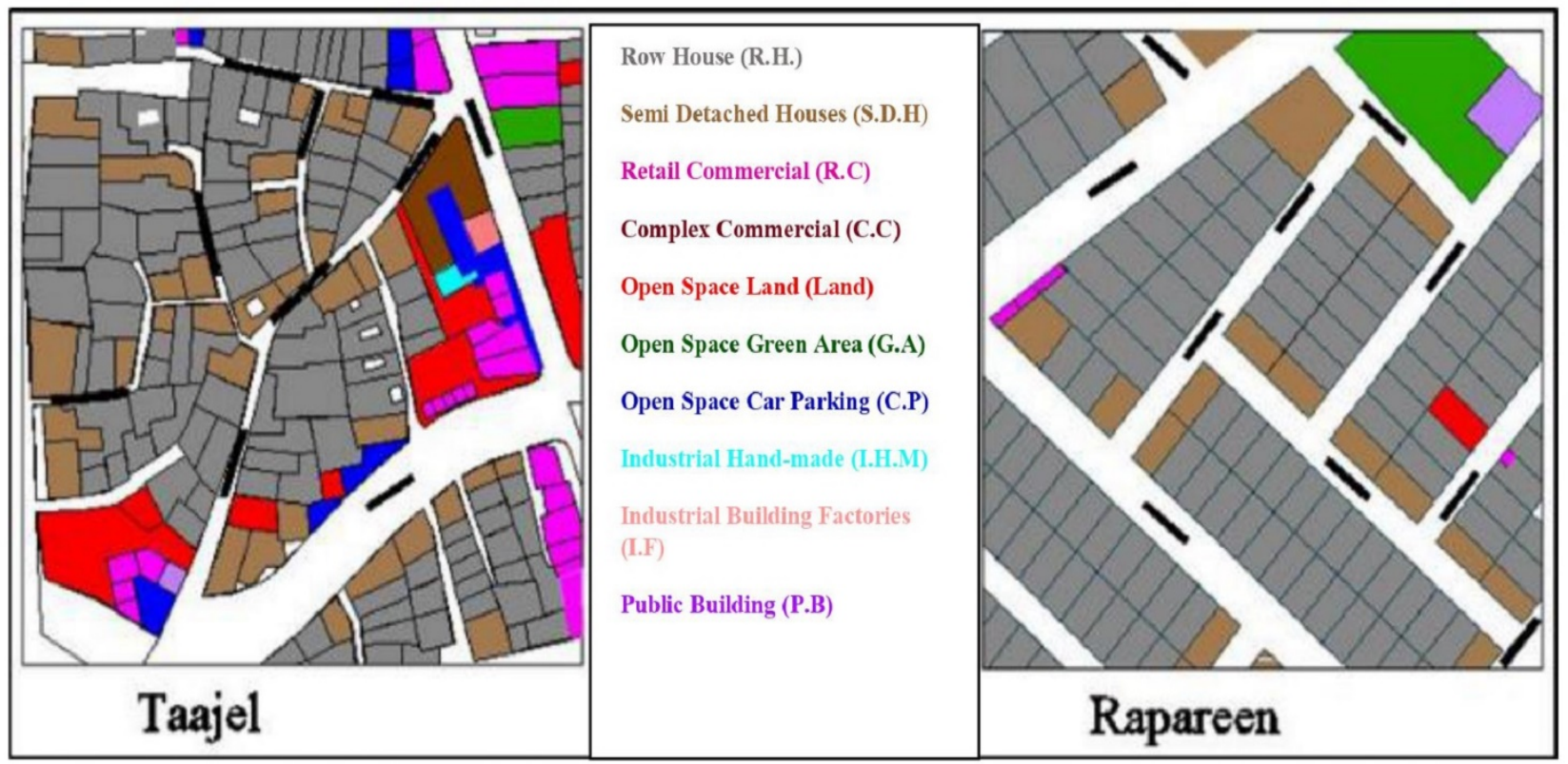

Figure 6. Land-use maps for Tajfel and Rapareen neighborhoods. (Developed by Researcher) 
According to 'SDI,' for 'teasel' neighborhood, the results demonstrated that the total number of categories (s) is 14 , while the total number of individuals $(\mathrm{N})$ is 184 . However, there is a need to mention that after applying the obtained data based on SDI formula (1), the Diversity in the Taajel neighborhood through the selected case study region was ' 2.784 '. It is worth mentioning that the bigger number refers to more diverse regions and, consequently, more complex. See table ' 1 '.

The researcher repeated the same procedure to find out the SDI for the 'Rapareen' neighborhood. The outcome has shown that the categories (s) are ' 9 ', and the whole number of individuals (N) is '143'. The results of SDI demonstrated that the Diversity in the 'Rapareen' neighborhood is ' 2.671 ', as per the selected case study within the neighborhood. See table ' 2 '.

The comparison between 'Taajel' and 'Rapareen,' in terms of Diversity, shows that Diversity in the former neighborhood is more than the latter. Thus, it is indicated that the Taajel neighborhood is more complex than the 'Rapareen' neighborhood, where more Diversity leads to more Complexity [41]. The traditional neighborhood is characteristic of various land-use than in the modernist neighborhood and the presence of various alleys with different widths, which is one of the main reasons why the traditional neighborhood of 'Taajel' is more complex than the modernist one in 'Rapareen.'

Table 1. The assessment of Diversity in 'Taajel' neighborhood, according to the SDI tool within the selected (200*200 m). (Developed by Researcher)

\begin{tabular}{|c|c|c|c|c|c|}
\hline \multicolumn{6}{|c|}{ Rapareen Neighbourhood } \\
\hline No. & Types & Categories (s) & $\begin{array}{c}\text { Individual } \\
\text { numbers (n) }\end{array}$ & $P i=(n / N)$ & $(\mathrm{Pi})^{\wedge} \mathbf{2}$ \\
\hline 1 & Building (Residential) & Row Houses & 109 & 0.602 & 0.36266 \\
\hline 2 & & Semi-detached & 18 & 0.099 & 0.00989 \\
\hline 3 & Building (commercial) & Retail & 4 & 0.022 & 0.00049 \\
\hline 4 & Public Building & Governmental & 1 & 0.006 & 0.00003 \\
\hline 5 & Open Space & Green & 1 & 0.006 & 0.00003 \\
\hline 6 & & Land & 1 & 0.006 & 0.00003 \\
\hline 7 & Street & $20.0 \mathrm{~m}$ width & 1 & 0.006 & 0.00003 \\
\hline 8 & & $15.0 \mathrm{~m}$ width & 2 & 0.011 & 0.00012 \\
\hline 9 & & $10.0 \mathrm{~m}$ width & 6 & 0.033 & 0.00110 \\
\hline \multicolumn{3}{|c|}{ Total } & 143 & & 0.37438 \\
\hline
\end{tabular}

Table 2. Diversity in the 'Rapareen' neighborhood based on the selected area's SDI tool (200*200 m). (Developed by Researcher)

\begin{tabular}{|c|c|c|c|c|c|}
\hline \multicolumn{6}{|c|}{ Taajel Neighbourhood } \\
\hline No. & Types & Categories (s) & $\begin{array}{c}\text { Individual } \\
\text { numbers } \\
\text { (n) }\end{array}$ & $\mathbf{P i}=(\mathbf{n} / \mathbf{N})$ & $(\mathrm{Pi})^{\wedge} \mathbf{2}$ \\
\hline 1 & Building (Residential) & Row Houses & 101 & 0.558 & 0.31138 \\
\hline 2 & & Semi-detached & 28 & 0.155 & 0.02393 \\
\hline 3 & Building (commercial) & Retail & 25 & 0.138 & 0.01908 \\
\hline 4 & & Complex & 1 & 0.006 & 0.00003 \\
\hline 5 & Building (Industrial) & Hand-made & 1 & 0.006 & 0.00003 \\
\hline 6 & & Fcatories & 1 & 0.006 & 0.00003 \\
\hline 7 & Public Building & Governmental & 1 & 0.006 & 0.00003 \\
\hline 8 & Open Space & Green & 1 & 0.006 & 0.00003 \\
\hline 9 & & Land & 9 & 0.050 & 0.00247 \\
\hline 10 & & Car-Parking & 6 & 0.033 & 0.00110 \\
\hline 11 & Street & $20.0 \mathrm{~m}$ width & 1 & 0.006 & 0.00003 \\
\hline 12 & & $10.0 \mathrm{~m}$ width & 1 & 0.006 & 0.00003 \\
\hline 13 & & $\begin{array}{l}5.0 \text { to } 6.0 \mathrm{~m} \\
\text { width }\end{array}$ & 4 & 0.022 & 0.00049 \\
\hline 14 & & Less than $5.0 \mathrm{~m}$ & 4 & 0.022 & 0.00049 \\
\hline \multicolumn{3}{|c|}{ Total } & 184 & & 0.35915 \\
\hline
\end{tabular}




\subsection{Energy Consumption Assessment}

The subsequent analysis will focus on a neighborhood scale. The purpose is to evaluate passive volume ratio (PVR) based on the complexity of urban fabric. The under-consideration zones are $200 \times 200 \mathrm{~m}$ square in each of traditional and modernist neighborhoods. In the traditional neighborhood of 'Taajel,' there are vernacular urban elements, as narrow and irregular alleys, with irregular shapes of lots and mixed land-use. The buildings clustered organically around numerous alleys with different widths allow much better integration of buildings with the outside environment and increase passive volume ratio (PVR). Firstly, determine the building's distribution and relationships with alleys and streets; then, finding the passive zones in the neighborhood-scale buildings.

With Auto-Cad files analysis and conventional calculation methods applied in excel sheets, the researcher found that total area of the buildings equals 27,930.65 square meters. Secondly, determining the passive zones line from the edge of the buildings with the outer environment was '2773.83' linear meters. Figure ' 7 ' displays the traditional district (Taajel neighborhood) and demonstrates the passive zone lines are in bold blue.

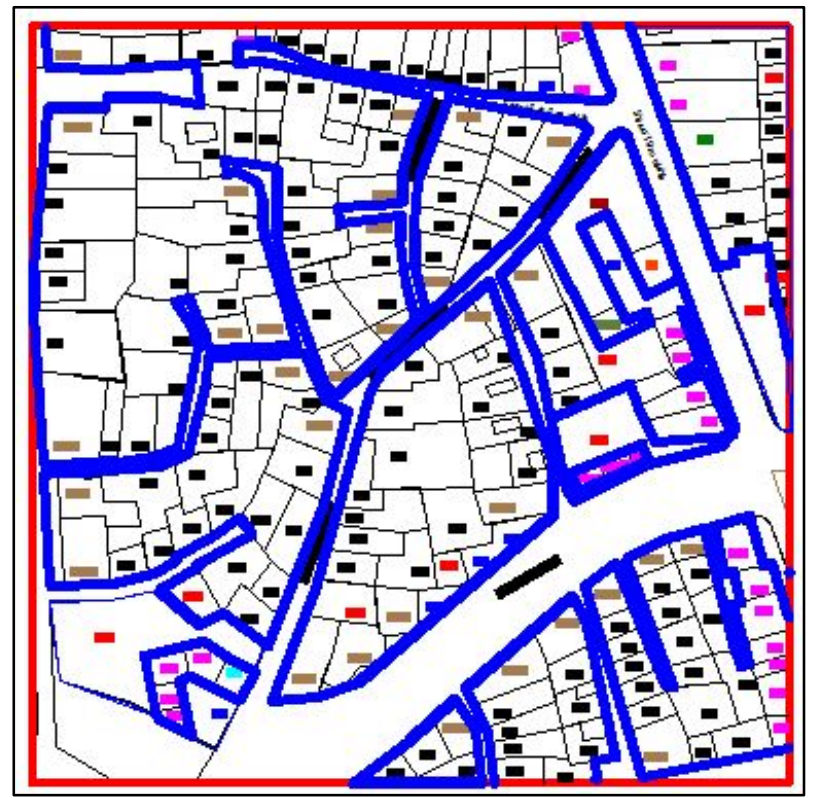

Figure 7. The passive zone lines in the 'Taajel' neighborhood selected zone. (Developed by Researcher).

Accordingly, considering the effect of the passive zone equal to six meters from the passive zone lines (Ratti et al., 2005), the total area of the passive zone is equal:

The Area of Passive zone $=2773.83 * 6=16642.98 \mathrm{~m}^{2}$

Hence, the total area for the passive zones in the studied area and found 16,642.98 square meters. The PVR can be obtained based on the acquired data by dividing the total passive zone area by total building area of the selected zones. Thus, the PVR for the traditional zone is $60 \%$. The researchers applied the same procedure over the neighborhood of Rapareen to evaluate PVR in the modernist neighborhood of Rapareen; following the analysis, the total built-up area was'26,245.14' square meters. Location of the passive zone lines has been determined, as seen in figure ' 8 ', and the lengths of the passive zone lines were 1704.65 meters. The passive zone area has found equal to $10,227.90$ square meters, and accordingly, the PVR for the modernist zone was 39\%.

The first zone in 'Taajel' or the traditional neighborhood, is vernacular urban because of this neighborhood's old characteristic. The modernist neighborhood of 'Rapareen' is made of simple rectangular blocks, without any curved alleys or irregular lots. The results demonstrate that the traditional neighborhood of 'Taajel' has a more passive volume ratio than the modernist neighborhood of Rapareen. Accordingly, this indicates that urban energy consumption in the traditional neighborhood is less than energy consumption in the modernist neighborhood because the passive zone will reduce energy consumption [18].

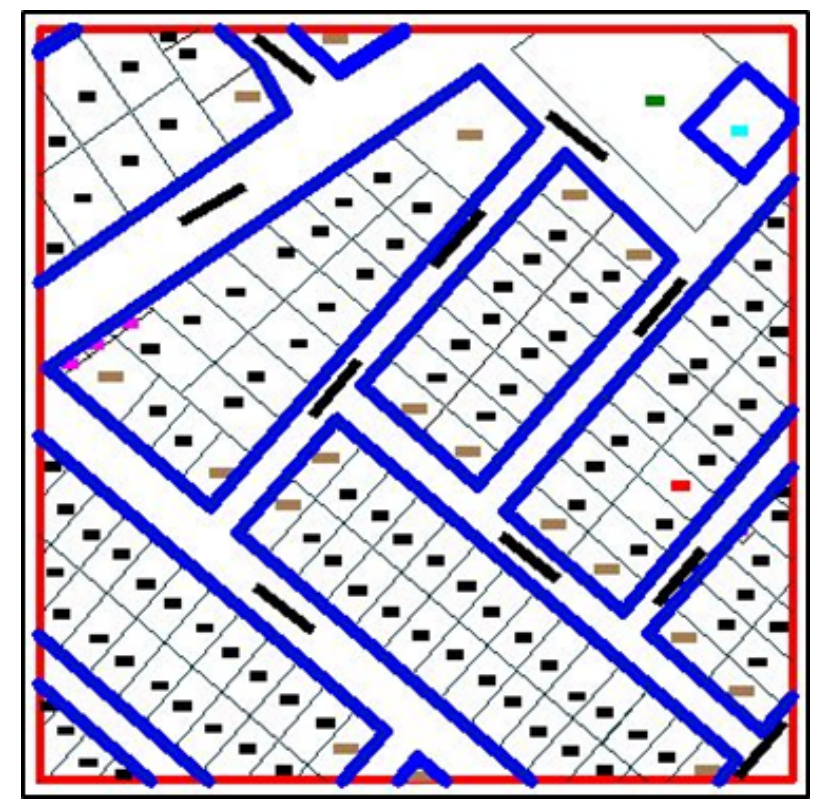

Figure 8. The passive zone lines in the selected zone of the 'Rapareen' neighborhood. (Developed by Researcher).

\section{Conclusion}

Several synergies between urban design and new knowledge coming from the complexity sciences, such as complexity theory, have been proposed by urbanists. The current paper has tried to offer an inclusive investigation of concepts and indicators that work as tools by authorities and urban planners to assess the urban complexity and its relationship with urban energy consumption. This study aimed to investigate the relationship between urban physical complexity and urban energy consumption. For this purpose, two different urban context characteristics 
have been selected in Erbil city for analysis in urban complexity assessment and energy consumption evaluation. The traditional urban setting of the 'Taajel' neighborhood serves as a case study to examine the relationships between the urban environment people and climate. Interact with nature, the sun, and the breeze as people stroll across its uneven lots and bending pathways established by humans.

On the contrary, modernist city planners set out abstract theories and principles about dominance of their proposal, simplicity, and right angles. In assessing complexity in the selected urban areas, the researcher used the SDI as an analytical tool. This tool considers Diversity as one of the dominant indicators of complexity assessment. Moreover, energy consumption of the urban area has been evaluated based on passive volume ratio 'PVR' as assess the tool. Considering a larger passive zone in an urban area compared with the total building area leads to less energy consumption.

Nevertheless, the study demonstrated that 'Taajel' is more complicated than the modernist neighborhood of 'Rapareen.' However, the passive volume ratio in the traditional neighborhood is higher than that in the modernist neighborhood. Accordingly, the finding supports that the greater the passive volume ratio, the more complex the urban tissue. See table ' 3 '.

Table 2. The comparison between the neighborhoods in terms of Complexity and PVR. (Developed by Researcher)

\begin{tabular}{|c|c|c|}
\hline Neighborhood & Complexity & PVR \\
\hline Traditional (Taajel) & 2.784 & $60 \%$ \\
\hline Modernist (Rapareen) & 2.671 & $39 \%$ \\
\hline
\end{tabular}

The higher the PVR, the less energy consumption in urban areas because of positive effect of passive zones on the energy efficiency in building areas. Thus, the previous table shows that higher physical complexity makes urban environments more energy efficient Furthermore, a modernist approach to urban planning cannot understand the complexity of traditional urban textures. As a result, these plans use less energy than traditional contexts.

\section{REFERENCES}

[1] World Urbanization Prospects: The 2018 Revision. UN, 2019. doi :10.18356/b9e995fe-en

[2] D. Satterthwaite, "Cities' contribution to global warming: notes on the allocation of greenhouse gas emissions," Environ. Urban., vol. 20, no. 2, pp. 539-549, Oct. 2008, doi: $10.1177 / 0956247808096127$.

[3] H. A. Khalil, "Energy Efficiency Strategies in Urban Planning of Cites," Aug. 2009, doi: 10.2514/6.2009-4622.

[4] M. A. Amen and H. A. Nia, "The dichotomy of society and urban space configuration in producing the semiotic structure of the modernism urban fabric," 2018, doi: doi.org/10.1515/sem-2016-0141 Abstract:

[5] M. L. Zellner, T. L. Theis, A. T. Karunanithi, A. S. Garmestani, and H. Cabezas, "A new framework for urban sustainability assessments: Linking complexity, information and policy," Comput. Environ. Urban Syst., vol. 32, no. 6, pp. 474-488, Nov. 2008, doi: 10.1016/j.compenvurbsys.2008.08.003.

[6] S. Salat, L. Bourdic, and C. Nowacki, "Assessing Urban Complexity,” Int. J. Sustain. Build. Technol. Urban Dev., vol. 1, no. 2, pp. 160-167, Dec. 2010, doi: 10.5390/SUSB.2010.1.2.160.

[7] M. Chowdhury et al., "Toll family members bind multiple Spätzle proteins and activate antimicrobial peptide gene expression in Drosophila," J. Biol. Chem., vol. 294, no. 26, pp. 10172-10181, Jun. 2019, doi: 10.1074/jbc.RA118.006 804.

[8] "Global Energy \& CO2 Status Report," Paris, 2019. [Online]. Available: https://www.iea.org/reports/global-en ergy-co2-status-report-2019

[9] C. Balocco, M. Cecchi, and G. Volante, "Natural Lighting for Sustainability of Cultural Heritage Refurbishment," Sustainability, vol. 11, no. 18, p. 4842, Sep. 2019, doi: 10.3390/su11184842.

[10] R. Thomas, Building desig. London: Spon Press., 2003.

[11] E. Burton, M. Jenks, and K. Williams, Eds., The Compact City. Routledge, 2003. doi:10.4324/9780203362372

[12] M. Alberti, "Urban form and ecosystem dynamics: Empirical evidence and practical implications," in Achieving Sustainable Urban Form, and M. J. K. Williams, E. Burton, Ed. London: E \& FN Spon., 2000

[13] M. Parker Pearson and C. Richards, Architecture and order : approaches to social space. 1994.

[14] I. Samuels, 'Achieving Sustainable Urban Form'. 'Compact Cities: Sustainable Urban Forms for Developing Countries,' vol. 6 , no. 3-4. 2001.

[15] J. Jacobs, The Death and Life of Great American Cities. Chichester, UK: Macat Library, 2017.

[16] S. Shackelford and D. Murray, "Developing a Freight Capacity Model for Land Use Planning and Air Quality Impact Analysis," in Transportation Land Use, Planning, and Air Quality, May 2008, pp. 241-249, doi: 10.1061/40960(320)23.

[17] P. Carl, "Urban density and block metabolism," in Architecture, city, environment. Proceedings of PLEA, 2000, pp. 343-347

[18] S. Salat and L. Bourdic, "Urban Complexity, Efficiency and Resilience," in Energy Efficiency - A Bridge to Low Carbon Economy, InTech, 2012.

[19] M. Batty, Cities and Complexity. Cambridge, MA: MIT Press, 2005.

[20] P. M. Allen, "Evolutionary Complex Systems: The Self-Organization of Communities," 1997, pp. 109-134.

[21] P. M. Allen, "Cities as Self-Organising Complex Systems," in The City and Its Sciences, Heidelberg: Physica-Verlag 
HD, 1998, pp. 95-144.

[22] J. Portugali, H. Meyer, E. Stolk, and E. Tan, Eds., Complexity Theories of Cities Have Come of Age. Berlin, Heidelberg: Springer Berlin Heidelberg, 2012.

[23] R. Rosen, "General System Theory. Foundations, Development, Applications. Ludwig von Bertalanffy. Braziller, New York, 1969. xvi + 290 pp., illus. Cloth, \$8.95; paper, \$3.95," Science (80-. )., vol. 164, no. 3880, pp. 681682, May 1969, doi: 10.1126/science.164.3880.681.

[24] J. Güell, F.; Miguel, "How to approach urban Complexity, Diversity, and uncertainty when involving stakeholders into the planning process9 - 99801 - 3 - 6. pp. 2780-2791.," Lisboa, Portugal, 2017.

[25] D. B. Lee, "Requiem for Large-Scale Models," J. Am. Inst. Plann., vol. 39, no. 3, pp. 163-178, May 1973, doi: $10.1080 / 01944367308977851$.

[26] M. Batty and P. Longley, Fractal cities. 1994.

[27] G. de Roo and E. A. Silva, A Planner's Encounter with Complexity. Routledge, 2016.

[28] T. I. Sanders, "Complex Systems Thinking and New Urbanism," in New Urbanism and Beyond, T. Haas, Ed. New York, USA: Rizzoli, 2008, pp. 275-279.

[29] E. TALEN, "Measuring Urbanism: Issues in Smart Growth Research,” J. Urban Des., vol. 8, no. 3, pp. 195-215, Oct. 2003, doi: 10.1080/1357480032000155141.

[30] K. Clifton, R. Ewing, G. Knaap, and Y. Song, "Quantitative analysis of urban form: a multidisciplinary review," J. Urban. Int. Res. Placemaking Urban Sustain., vol. 1, no. 1, pp. 17-45, Mar. 2008, doi: 10.1080/17549170801903496.

[31] R. Ewing and R. Cervero, "Travel and the Built Environment," J. Am. Plan. Assoc., vol. 76, no. 3, pp. 265294, Jun. 2010, doi: 10.1080/01944361003766766.

[32] N. Schwarz, "Urban form revisited-Selecting indicators for characterising European cities," Landsc. Urban Plan., vol. 96, no. 1, pp. 29-47, May 2010, doi: 10.1016/j.landurbplan.2010.01.007.

[33] Y. Song and G.-J. Knaap, "Measuring Urban Form: Is Portland Winning the War on Sprawl?," J. Am. Plan. Assoc., vol. 70, no. 2, pp. 210-225, Jun. 2004, doi: $10.1080 / 01944360408976371$.

[34] L. Bourdic, S. Salat, and C. Nowacki, "Assessing cities: a new system of cross-scale spatial indicators," Build. Res. Inf., vol. 40, no. 5, pp. 592-605, Oct. 2012, doi: 10.1080/09613218.2012.703488.

[35] L. Parrott, "Measuring ecological complexity," Ecol. Indic., vol. 10, no. 6, pp. 1069-1076, Nov. 2010, doi: $10.1016 /$ j.ecolind.2010.03.014.
[36] G. Boeing, “OSMnx: New methods for acquiring, constructing, analyzing, and visualizing complex street networks," Comput. Environ. Urban Syst., vol. 65, pp. 126139, 2017, doi: 10.1016/j.compenvurbsys.2017.05.004.

[37] E. Dumbaugh, W. Li, and K. Joh, "The built environment and the incidence of pedestrian and cyclist crashes," URBAN Des. Int., vol. 18, no. 3, pp. 217-228, Aug. 2013, doi: 10.1057/udi.2013.2.

[38] S. Marshall, Cities Design and Evolution. New York, United States, 2008.

[39] G. Boeing, "Measuring the complexity of urban form and design,” URBAN Des. Int., vol. 23, no. 4, pp. 281-292, Nov. 2018, doi: 10.1057/s41289-018-0072-1.

[40] M. A. Amen and H. A. Nia, "The effect of centrality values in urban gentrification development: A case study of erbil city," Civ. Eng. Archit., vol. 8, no. 5, pp. 916-928, 2020, doi: 10.13189/cea.2020.080519.

[41] J. Dibble et al., "Urban Morphometrics: Towards a Science of Urban Evolution,” vol. 2015, pp. 1-14, 2015, [Online]. Available: http://arxiv.org/abs/1506.04875.

[42] R. Cervero and K. Kockelman, "Travel demand and the 3Ds: Density, diversity, and design," Transp. Res. Part D Transp. Environ., vol. 2, no. 3, pp. 199-219, Sep. 1997, doi: 10.1016/S1361-9209(97)00009-6.

[43] U. Wissen Hayek et al., "Quality of urban patterns: Spatially explicit evidence for multiple scales," Landsc. Urban Plan., vol. 142, pp. 47-62, Oct. 2015, doi: 10.1016/j.landurbplan.2015.05.010.

[44] M. A. Amen, "The inspiration of Bauhaus principles on the modern housing in Cyprus," J. Contemp. Urban Aff., vol. 1, no. 2, pp. 21-32, Dec. 2017, doi: 10.25034/ijcua.2017.3645.

[45] P. J. Somerfield, K. R. Clarke, and R. M. Warwick, "Simpson Index," in Encyclopedia of Ecology, Elsevier, 2008, pp. 3252-3255.

[46] C. Ratti, N. Baker, and K. Steemers, "Energy consumption and urban texture," Energy Build., vol. 37, no. 7, pp. 762776, Jul. 2005, doi: 10.1016/j.enbuild.2004.10.010.

[47] N. Baker and K. Steemers, "LT Method 3.0 - a strategic energy-design tool for Southern Europe," Energy Build., vol. 23, no. 3, pp. 251-256, Mar. 1996, doi: $10.1016 / 0378-7788(95) 00950-7$.

[48] S. S. M. Al-Din, M. Iranfare, and Z. N. S. Surchi, "Building Thermal Comfort Based on Envelope Development: Criteria for selecting right case study in Kyrenia- North Cyprus," Energy Procedia, vol. 115, pp. 80-91, Jun. 2017, doi: 10.1016/j.egypro.2017.05.009.

[49] M. Cencini, F. Cecconi, and A. Vulpiani, Chaos, vol. 17. WORLD SCIENTIFIC, 2009. 